\title{
SELF-ESTEEM OF PEOPLE WHO PRACTICE SPORT IN RELATION TO THEIR EXPERIENGING THE FLOW STATE AND THEER STYLE OF COPING WIIT STRESS
}

\author{
Marzena Tomczak, 1, A, B, C, D Maria Alicja Nowak2, A, D, E \\ ${ }^{1}$ University School of Physical Education in Poznań, Faculty of Physical Culture in Gorzow Wielkopolski, Poland \\ ${ }^{2}$ The University of Szczecin, Faculty of Physical Culture and Health Promotion, Poland \\ A Study Design; ${ }^{\mathrm{B}}$ Data Collection; ${ }^{\mathrm{C}}$ Statistical Analysis; ${ }^{\mathrm{D}}$ Manuscript Preparation; ${ }^{\mathrm{E}}$ Funds Collection \\ Address for correspondence: \\ Marzena Tomczak \\ Faculty of Physical Culture, \\ Estkowskiego 13, 66-400 Gorzów Wlkp., Poland, \\ E-mail: tomczak@awf-gorzow.edu.pl
}

\begin{abstract}
Ahstract The purpose of this work was to ascertain the association of the level of athletes' self-esteem with their stress management and experiencing the flow state. The study included 56 men and 18 women, aged 19 to 25 , who practiced sport and lived in Gorzów Wielkopolski and its vicinity. The following tools were employed: the Rosenberg Self-Esteem Scale, N.S. Endler and J.D. Parker's Coping Inventory for Stressful Situations (CISS), and S. Jackson and D. Eklund's Flow State Scale - 2. For the analysis of variables descriptive statistics, correlation measures (Pearson's $r$ ) and regression analysis were used. It was found that there is a positive correlation at the level of 0.05 between high self-esteem and the task-oriented style of coping with stressful situations, and a significant negative correlation at the level of 0.01 between self-esteem and the emotion-oriented style of stress management. The level of self-esteem also correlates with experiencing the flow state. Self-esteem is an important predictor of the method of coping with stressful situations and experiencing the flow state. People with higher self-esteem achieve the state of a kind of felicity, an autotelic experience. They are aware of their own abilities, have the feeling that they effortlessly control their situation and themselves, and can distance themselves from the surrounding environment. In a stressful situation, they focus on the problem.
\end{abstract}

Key WOrdls self-evaluation, flow, stress, style of coping, athletes

\section{Introduction}

One of the ways good life is expressed is through a sense of successful coping with all adversities that are an integral part of human existence. It is connected with the willingness to experience satisfaction with actions taken on the one hand, and with the ability to cope with difficult situations on the other.

The flow state indicates optimal engagement, elation associated with the state of mind in a situation of taking actions in which the challenges correspond to the skills, and where the objective is not the result but the action itself. 
One of the main assumptions of the flow experience is that the challenges must match the skills (Csikszentmihalyi, 2005).

An individual style of coping with difficulties (Endler, Parker, James, 1994) means putting emphasis on a certain general and more abstract way of taking action, superior to the choice of strategy, manifested in longer time perspectives, and in the assessment of distant consequences, concerning e.g. health, social functioning or sport achievements. This kind of approach offers the basis for the search for people's individual preferences in coping with stress, also in the field of sport.

Out of many personality characteristics, self-esteem and self-evaluation seem to be especially significant determinants of the way people function in the physical, social and mental spheres. For example, children who successfully cope with school requirements become convinced of their own competences. The kind of feedback received and the way it is interpreted has a very strong influence on a person's self-image (Harter, Whitesell, 2003).

Self-esteem is a conviction of the positivity and importance of one's self, which is strongly connected with the level of one's self-evaluation, defined as the anticipation of one's own capacity, depending on the tasks and circumstances (Epstein, 1992). Self-esteem denotes subjective experiencing of oneself as a value, and its indicator is a comprehensive self-evaluation, being a subjectively experienced overall evaluation of oneself (Rosenberg, Schooler, Schoenbach, Rosenberg, 1995). M. Rosenberg and psychologists of social learning treated the sense of personal value or valuableness as a relatively permanent trait of personality, measured by self-evaluation, being a measure of a person's well-being.

The pursuit of a high self-esteem plays an important role in human life. People seek to achieve success in areas which are important for them, thus satisfying, as some researchers argue, one of the primary needs. A high self-esteem can also be instrumental, as it brings several benefits, such as a sense of security in social relations, which eliminates rejection and exclusion, or a diminished fear of death (Pyszczyński's concept of anxiety control) (Solomon, Greenberg, Pyszczyński, 1991). It is also an important determinant of efficiency and the feeling of satisfaction with the work done (Kuster, Orth, Meier, 2013). Such benefits stemming from a high self-esteem can determine the way a person functions. They can, for example, be inclined to experience positive emotions, look upon themselves and the world optimistically, and have confidence as to the effectiveness of their own actions.

It is therefore to be expected that individuals with a high self-esteem will exhibit the characteristics of an autotelic personality, inclined to experience elation only when that self-esteem is based on real and authentic inner qualities, and not on the conviction that it is conditioned by personal achievements. The aspiration to put continually increasing demands upon oneself and, most of all, the striving for recognition of other people, are the basis of a high self-esteem, but can also be a source of stress. Seeking external gratification will be an obstacle to achieving optimal engagement and satisfaction with actions taken. The constant search for confirmation of one's greatness is connected with an exaggerated sense of self-magnitude in narcissistic people (Brummelman, Thomaes, Sedikides, 2016; Leckelt, Küfner, Nestler, Back, 2015).

Self-esteem is significantly related to stress. On the one hand, it influences the way stressogenic stimuli are treated and the choice of strategies for coping with them, and on the other hand, the experience of stress can lead to a lower self-esteem and contribute to a greater sense of insecurity, and non-adaptive responses (Doyle, Slaven, 2004). Most studies show that people with a high self-esteem are strong, mentally resilient and able to cope with threats and challenges. They treat challenges as new opportunities, stimulating and motivating them to take action, inspiring them to pursue new achievements and to draw satisfaction from them. People with a low 
self-esteem, in turn, are less resistant to difficult situations, lack confidence in their own abilities. As a result, depressive behaviors may occur (Lee, Hankin, 2009) and sometimes antisocial behaviors such as aggression and crime (Donnellan, Trzesniewski, Robins, Moffitt, Caspi, 2005). The study of volleyball players, by Terelak (2008), indicates that self-evaluation influences the style of coping with stress. A higher level of self-evaluation correlates with the task-oriented style. The lower the self-evaluation, the more likely volleyball players (both female and male) are to use the style that focuses on emotions.

People who practice sports are characterized by an optimistic attitude, self-esteem, self-reliance, and desire to overcome obstacles and win. They feel that everything depends on their own strength, skills and abilities, as well as their self-discipline and strong belief in their own effectiveness, resilience and perseverance (Laborde, Guillén, Mosley, 2016).

The aim of the present work was to ascertain the relationship of self-evaluation with coping with stress and experiencing the flow. From the point of view of psychologists and pedagogues, these variables are crucial for educational interactions, which enable young people to successfully cope with the requirements of their environment and make it possible to achieve satisfaction with their lives.

The following hypotheses were made:

1. There is a relationship between self-esteem of people who practice sport and their experiencing the flow phenomenon.

2. There is also a relationship between athletes' self-esteem and their style of coping with stressful situations.

\section{Material and methods}

In the study purposeful sampling was used, involving the selection of subjects who had a defined (desirable) property or experience relevant to the purpose of the study. The study embraced 74 people practicing sports at a competitive level, ranging in age from 19 to 25 , including 18 women and 56 men. The subjects were mostly athletes studying at the Faculty of Physical Culture in Gorzów Wielkopolski, being a branch of the University School of Physical Education in Poznań, as well as people training in sports clubs in the Gorzów region.

The average length of sports practiced by the respondents is $9.39 \pm$ years. Most athletes $(60.8 \%)$ practiced team sports such as football, volleyball or handball. They represented teams that had been oscillating between the first and the third leagues in recent years. Individual sports were practiced by $39.2 \%$ of the athletes, among whom canoeists were at a particularly high level.

In the operationalization of variables, M. Rosenberg's Self-Esteem Scale was used (Laguna, LachowiczTabaczek, Dzwonkowska, 2007), as well as N.S. Endler and J.D.A. Parker's Coping Inventory for Stressful Situations (CISS) (Strelau, Jaworowska, Wrześniewski, Szczepaniak, 2005), and S. Jackson and D. Eklund's Flow State Scale -2.

The self-esteem questionnaire is a tool that makes it possible to determine the level of general self-esteem, regarded as a relatively constant disposition to take a conscious attitude - positive or negative - toward Self. The scale consists of 10 diagnostic statements that have a high internal consistency of most scales (Cronbach's alpha coefficients for different age groups range from 0.81 to 0.83 ). The range of results obtained during the questionnaire survey is between 10 and 40 . The higher score a person gets on a scale, the higher self-esteem level they have. 
Endler and Parker developed a questionnaire that ascertains one's style of coping with stress. The questionnaire has a high internal consistency of particular scales, as Cronbach's alpha coefficients range from 0.78 to 0.90 (Szczepaniak, Strelau, Wrześniewski, 1996).

Flow State Scale - 2 is a tool developed by Jackson and Eklund to measure optimum involvement in a group of athletes. The questionnaire consists of 36 statements, and individuals can score between 36 and 180 points. The overall score consists of 9 dimensions: challenge-skill balance, action-awareness merging, setting clear goals, receiving feedback, concentration on the task at hand, paradoxical loss of control, loss of self-consciousness, time transformation, and one of the main and necessary conditions, namely the autotelic experience. The questionnaire is a tool that has a high internal consistency in the nine subscales and the general flow scale, as indicated by Cronbach's alpha coefficients ranging from 0.80 to 0.90 (Koehn, 2007).

The Flow State Scale - 2 questionnaire was adapted for the purpose of this study. The translation of the original version was carried out by three independent people. Out of the options offered, the convergent ones were chosen, and they were further modified so that they both sound correct in the Polish language and accurately render the essence and content of each scale. Following the survey, information concerning comprehensibility and clarity of the set statements was collected. In the present study, Cronbach's alpha coefficients were lower and ranged from 0.58 to 0.78 .

The results presented in this paper are part of research carried out since 2014 in Gorzów Wielkopolski at the Faculty of Physical Culture of the University School of Physical Education in Poznań into psychological determinants of competitive sport, including the formation of athletes' self-esteem.

The research was carried out in a correlation-regression model, which in the case of analyzing the relationship between self-esteem and optimal engagement and stress coping style, becomes the one-variable - multi-variable variant. In the analysis of the variables, descriptive statistics, correlation measures (Pearson's $r$ ) and regression analysis were used.

\section{Results}

The average self-evaluation score obtained by the subjects was 28.64 points (Table 1). Half of the subjects scored 29 points or fewer, and half scored 29 or more, which indicates a fairly high level of self-evaluation among the respondents, but lower than in the comparable 19-24 age group (Laguna et al., 2007).

Out of the three coping styles, the task-oriented one had the highest average (57.49), which indicates its dominance among both male and female athletes who practice sports at a competitive level. The level of the emotion-oriented style of coping with difficulties was slightly lower: this was caused by the difference in the results between the genders. As expected, women were characterized by a higher level of the emotion-oriented coping style.

The average score for the flow state experience amounted to 130.28 points. The examined athletes declared a fairly good ability to experience optimal engagement. The score obtained by the greatest number of the subjects was 124. Clear goals and willingness to derive pleasure from sport and rivalry were the most commonly chosen flow dimensions. Autotelic experience is an action that is an end in itself, performed not for reward, but for the sole pleasure of doing it. According to Csikszentmihalyi (2005), it transfers a person to a higher level, justifying life in the present, bringing freedom from the necessity of attaining future goals. The athletes had the greatest difficulty with 
getting rid of self-consciousness, which is expressed in being somewhat carried away, not thinking about oneself or the people watching, thereby expanding the boundaries of one's own being.

Table 1. Descriptive statistics for the subscales of the Coping Inventory for Stressful Situations (CISS), the Flow State Scale - 2 and the SES

\begin{tabular}{|c|c|c|c|c|c|}
\hline Scale & Subscale & Min & Max & Average $\bar{x}$ & Standard deviation \\
\hline \multirow[t]{3}{*}{ SES } & & 21 & 39 & 28.64 & 3.61 \\
\hline & Task-oriented style & 40 & 74 & 57.49 & 7.03 \\
\hline & Emotion-oriented style & 27 & 69 & 50.14 & 7.98 \\
\hline \multirow[t]{7}{*}{ CISS } & Avoidance & 21 & 44 & 33.32 & 5.54 \\
\hline & Distraction & 11 & 31 & 23.55 & 4.55 \\
\hline & Social Diversion & 7 & 25 & 17.69 & 3.46 \\
\hline & Flow & 89 & 175 & 130.28 & 18.81 \\
\hline & Clear goals & 10 & 20 & 15.91 & 2.40 \\
\hline & Challenge-skill balance & 7 & 20 & 14.89 & 2.69 \\
\hline & Concentration on task & 7 & 20 & 14.08 & 2.49 \\
\hline Flow State & Paradox of control & 4 & 20 & 14.72 & 3.16 \\
\hline \multirow[t]{5}{*}{ Scale - 2} & Unambiguous feedback & 9 & 20 & 14.19 & 2.51 \\
\hline & Action-awareness merging & 7 & 20 & 13.66 & 2.70 \\
\hline & Time transformation & 7 & 20 & 13.92 & 2.56 \\
\hline & Loss of self-consciousness & 4 & 20 & 13.31 & 4.73 \\
\hline & Autotelic experience & 8 & 20 & 15.61 & 2.97 \\
\hline
\end{tabular}

The correlation results shown in Table 2 a significant positive correlation at the 0.05 level. It points to interconnections between the level of optimal engagement and the level of self-evaluation.

Table 2. Results of Pearson's $r$ correlation between self-esteem and the flow scales

\begin{tabular}{lc}
\hline \multicolumn{1}{c}{ Flow scales } & Self-esteem scale \\
\hline Flow & $0.24^{*}$ \\
Clear goals & 0.19 \\
Challenge-skill balance & $0.34^{* *}$ \\
Concentration on task & 0.09 \\
Paradox of control & $0.37^{* *}$ \\
Unambiguous feedback & 0.23 \\
Action-awareness merging & -0.22 \\
Time transformation & -0.06 \\
Loss of self-consciousness & $0.25^{*}$ \\
Autotelic experience & $0.28^{*}$ \\
\hline
\end{tabular}

"Correlation is significant at the 0.05 level (two-tailed).

"Correlation is significant at the 0.01 level (two-tailed).

As far as the scales which make up the overall flow result are concerned, significant positive correlations could be observed at the 0.01 level in the challenge-skill balance scale, and in the control paradox scale. Athletes with 
a high level of self-evaluation were aware of their own competencies, and therefore could meet the demands of the situation and control their thoughts, emotions and behavior. Significant positive correlations at the 0.05 level occurred between the self-evaluation level and the loss of self-consciousness and the autotelic experience. Individuals with a high self-evaluation do not pay attention to surrounding people, to how they are judged or perceived by others, seeking positive experiences and satisfaction in each occurrence.

Table 3. Results of Pearson's $r$ correlation between self-esteem and the stress coping style

\begin{tabular}{lc}
\hline \multicolumn{1}{c}{ Styles } & Self-esteem scale \\
\hline Task-oriented style & $0.30^{*}$ \\
Emotion-oriented style & $-0.52^{* *}$ \\
Avoidance style & -0.15 \\
Distraction & 0.08 \\
Social Diversion & -0.04 \\
\hline
\end{tabular}

"Correlation is significant at the 0.05 level (two-tailed)

" Correlation is significant at the 0.01 level (two-tailed).

Table 3 contains the correlation results which verify the hypothesis. There was a positive correlation at the 0.05 level, indicating interconnections between a high self-esteem and the task-oriented style of coping with a stressful situation. It is self-esteem and confidence in one's own competences and ability to perform tasks that prove helpful in difficult situations, resulting in a rational, task-oriented approach to the problem. The results also revealed the relationships which ascertained a significant negative correlation between self-evaluation and the emotion-oriented coping style. The determination coefficient was 0.265 , so the emotion-oriented style of coping with stress in $26.5 \%$ of the competition-level sportspeople can be explained by their low self-evaluation. Based on the regression analysis (Table 4), self-esteem can be assumed to be an important predictor of the methods of coping with difficult, stressful situations, as well as experiencing the flow state.

Tahle 4. Significance of the full regression model

\begin{tabular}{lcccccc}
\hline \multicolumn{1}{c}{ Dependent variables } & $\mathrm{R}$ & $\mathrm{R}^{2}$ & df model & df residual & $\mathrm{F}$ & $\mathrm{p}$ \\
\hline Flow & 0.24 & 0.06 & 1 & 72 & 4.48 & 0.03 \\
Clear goals & 0.19 & 0.03 & 1 & 72 & 2.56 & 0.11 \\
Challenge-skill balance & 0.34 & 0.12 & 1 & 72 & 9.57 & 0.00 \\
Concentration on task & 0.09 & 0.01 & 1 & 72 & 0.55 & 0.46 \\
Paradox of control & 0.37 & 0.13 & 1 & 72 & 11.08 & 0.00 \\
Unambiguous feedback & 0.23 & 0.05 & 1 & 72 & 3.88 & 0.05 \\
Action-awareness merging & 0.22 & 0.05 & 1 & 72 & 3.53 & 0.06 \\
Time transformation & 0.06 & 0.00 & 1 & 72 & 0.30 & 0.59 \\
Loss of self-consciousness & 0.25 & 0.06 & 1 & 72 & 4.65 & 0.03 \\
Autotelic experience & 0.28 & 0.08 & 1 & 72 & 6.18 & 0.01 \\
Task-oriented style & 0.3 & 0.09 & 1 & 72 & 6.94 & 0.01 \\
Emotion-oriented style & 0.52 & 0.27 & 1 & 72 & 26.05 & 0.00 \\
Avoidance style & 0.15 & 0.02 & 1 & 72 & 1.65 & 0.20 \\
\hline
\end{tabular}

$\mathrm{R}$ - multiple correlation coefficient; $\mathrm{R}^{2}$ - multiple determination factor; $\mathrm{F}$ and $\mathrm{p}$ - significance of the entire regression model. 


\section{Discussion}

Experiencing the flow state is a mental process that allows an individual to define precisely their body and spirit capabilities. This is difficult to achieve with low self-esteem and the emotion-oriented style of coping with stress. The experience of optimal engagement during sport rivalry seems to be possible when a person becomes self-confident and can rationally approach every situation, with the focus on resolving the problem.

An important aspect of the educational influence has been the building of high and stable self-evaluation of the athlete, which is the basis for predicting one's own capabilities. Baumeister et al., pointing to the undisputed benefits of high self-evaluation, emphasize that individuals with high self-evaluation feel that they are better and happier people and show greater initiative, also in interpersonal contacts (Baumeister, Campbell, Krueger, Vohs, 2003). High evaluation is an effective stress buffer for them. These positive aspects of high self-evaluation were confirmed in the present study. However, in his deliberations on self-evaluation Baumeister undermines the essence of high self-evaluation, and most of all the various types of impact aimed at its elevation.

A similar approach to self-evaluation is presented by Cocker and Park (2003) and Gustafsson et al., who point to the costs associated with pursuing goals whose realization is to be a confirmation of self-esteem (Gustafsson, Martinent, Isoard-Gautheur, Hassmen, Guillet-Descas, 2018). The authors believe that the pursuit of high self-evaluation interferes with making social relationships, learning, competence development, autonomy, self-regulation, and physical and mental health. According to Deci and Ryan (2000), orientation toward developing the natural need for competence, autonomy and relatedness should become the basis of our interactions in different areas of life, including sport. Realization of these needs increases internal motivation, self-regulation and wellbeing. The most important role in education is played by parents; their influence is stronger than that of the coach. Research shows that parents' initiating a favorable environment which is motivating for development, is a significant predictor of the levels of self-evaluation, anxiety as a quality, and autonomous regulation in future years (O'Rourke, Smith, Smoll, Cumming, 2014).

According to F.R. Baumeister et al. (2003), it is achievements that raise self-esteem, and not vice versa. Therefore, it becomes crucial that the work with athletes should be oriented toward developing perseverance and ability to pursue their own goals and ideals. Thus, self-control and self-discipline, which can be shaped and developed from an early age, are definitely more important components of one's personality. This development of self-control brings far more benefits. Higher self-control correlates with higher self-evaluation, better relationships and interpersonal skills, regulation of emotional reactions, a sense of security and decreased psychopathological behavior, as well as alcohol and food abuse (Tangney, Baumeister, Boone, 2014).

Such reformulation encourages a slightly different view on the education of a child and an athlete, with perseverance, diligence, self-discipline, composure and self-control at its core, which leads to achievements and success, and consequently to high self-esteem. Physical activity and sport develop these qualities and bring many different psychological, social and health benefits such as higher self-evaluation, improved social interactions, and decreased depressive symptoms (Eime, Young, Harvey, Charity, Payne, 2013). Physical activity improves the quality of life not only for the elderly, but also for adolescents, and the mediating factors are self-evaluation of one's physical competences and a sense of self-efficacy (Joseph, Royse, Benitez, Pekmezi, 2014; Piasecka, Kolmetz, Kotyśko, Stankiewicz, 2018). According to research (Noordstar, Van der Netb, Jakc, Heldersb, Jongmansd, 2016), physical activity and the perception of athletic competencies correlate, especially in girls, with global self-evaluation, 
but this has not been confirmed for boys, who have a higher level of athletic competencies and are more physically active than girls.

It seems that physical activity may be an important preventive factor, especially in the context of research which reports that both the level of and change in self-evaluation have served as predictors for depression occurrence. Individuals who entered adolescence with low self-evaluation and/or their self-evaluation lowered in adolescence, were more likely to display symptoms of depression in adulthood (Steiger, Allemand, Robins, Fend, 2014).

Therefore, the realization of one's goals should not only be connected with the affirmation of self-esteem, but with other needs of an individual. Research shows that greater joy of practicing sports will over time result in higher self-evaluation among young people, and higher self-evaluation, in turn, increases the pleasure of practicing sports. These studies suggest that the pleasure brought by practicing sport may be more important for self-evaluation than the frequency with which young people practice (Adachi, Willoughby, 2014). Thus, the desired skill that can be developed even in young children is experiencing flow. In fact, it often comes to maintaining this skill, because small children have a natural inclination to take actions which they enjoy. It is often the adult world that expects certain results of actions taken, which are more important than the actions themselves. Therefore, one's ability to set clear goals for themselves, adjusted to their capacity, using feedback, concentrating on the task at hand, paradoxical loss of control, separating oneself from other people's judgment and the passage of time, and finally the ability to derive pleasure from what one is doing becomes a potential for experiencing a good and happy life.

\section{Conclusions}

1. An important predictor of the method of coping with stress and of experiencing the flow state by individuals who practice sport is their level of self-esteem.

2. Athletes higher self-esteem is an indicator of their achieving the state of optimal engagement, which determines how effective their actions are, as well as how much pleasure they derive from their activities. Thus, it can be assumed that people with higher self-esteem experience the state of a kind of felicity, an autotelic experience. They are aware of their own abilities, they have the feeling that they effortlessly control their situation and themselves; at the same time, they can distance themselves from the surrounding environment.

3. The results of this study show that people with high self-esteem will prefer the task-oriented style of coping with stress, while people with low self-esteem will tend to cope with problems emotionally in difficult situations.

\section{References}

Adachi, P.J.C., Willoughby, T. (2014). It's Not How Much You Play, but How Much You Enjoy the Game: The Longitudinal Associations Between Adolescents' Self-Esteem and the Frequency Versus Enjoyment of Involvement in Sports. Journal of Youth and Adolescence, 43 (1), 137-145. DOI: 10.1007/s10964-013-9988-3.

Baumeister, R.F., Campbell, J.D., Krueger, J.I., Vohs, K.D. (2003). Does high self-esteem cause better performance, interpersonal success, happiness, or healthier lifestyles? Psychological Science in the Public Interest, 4(1), 1-44. DOI: 10.1111/1529-1006.01431.

Brummelman, E., Thomaes, S., Sedikides, C. (2016). Separating Narcissism From Self-Esteem. Current Directions in Psychological Science, 25 (1), 8-13. DOI: 10.1177/0963721415619737.

Crocker, J., Park, L.E. (2004). The Costly Pursuit of Self-Esteem. Psychological Bulletin, 130 (3), 392-414. DOI: 10.1037/0033-2909.130.3.392.

Csikszentmihalyi, M. (2005). Flow. Taszów: Biblioteka Moderatora.

Deci, E.L., Ryan, R.M. (2000). Intrinsic and Extrinsic Motivations: Classic Definitions and New Directions. Contemp Educ Psychol., 25, 54-67. DOI: 10.1006/ceps.1999.1020. 
Donnellan, M.B., Trzesniewski, K.H., Robins, R.,W., Moffitt, T. E., Caspi, A. (2005). Low Self-Esteem Is Related to Aggression, Antisocial Behavior, and Delinquency. Psychological Science, 16 (4), 328-335. DOI: 10.1111/j.0956-7976.2005.01535.x.

Doyle, Ch., Slaven, G. (2004). The relationship between negative behavior in affects and unfavorable reactions for stressors. In: J. Strelau (ed.), Personality and extreme stress (pp. 141-166). Gdańsk: GWP.

Eime, R.M., Young, J.A., Harvey, J.T., Charity, M.J., Payne, W.R. (2013). A systematic review of the psychological and social benefits of participation in sport for children and adolescents: informing development of a conceptual model of health through sport. International Journal of Behavioral Nutrition and Physical Activity, 10 (1). DOI: 10.1186/1479-5868-10-98.

Endler, N.S., Parker, J.D.A., James D.A. (1994). Assessment of multidimensional coping: Task, emotion, and avoidance strategies. Psychological Assessment, 6 (1), 50-60. DOI: 10.1037/1040-3590.6.1.50.

Epstein, S. (1992). Coping ability, negative self-evaluation, and overgeneralization: Experiment and theory. Journal of Personality and Social Psychology, 62 (5), 826-836. DOI: 10.1037/0022-3514.62.5.826.

Gustafsson, H., Martinent, G., Isoard-Gautheur, S., Hassmen, P., Guillet-Descas, E. (2018). Performance based self-esteem and athlete-identity in athlete burnout: A person-centered approach. Psychology of Sport and Exercise, 38, 56-60. DOI: 10.1016/j. psychsport.2018.05.017.

Harter, S., Whitesell, N.R. (2003). Beyond the Debate: Why Some Adolescents Report Stable Self-Worth Over Time and Situation, Whereas Others Report Changes in Self-Worth. Journal of Personality, 71 (6), 1027-1058. DOI: 10.1111/1467-6494.7106006.

Joseph, R.P., Royse, K.E., Benitez, T.J., Pekmezi. D.W. (2014). Physical activity and quality of life among university students: exploring self-efficacy, self-esteem, and affect as potential mediators. Quality of Life Research, 23 (2), 659-667. DOI: 10.1007I s11136-013-0492-8.

Koehn, S. (2007). Propensity and attainment of flow state. Melbourne: Victoria University.

Kuster, F., Orth, U., Meier, L.L. (2013). High self-esteem prospectively predicts better work conditions and outcomes. Social Psychological and Personality Science, 4 (6), 668-675. DOI:10.1177/1948550613479806.

Laborde, S., Guillén, F., Mosley, E. (2016). Positive personality-trait-like individual differences in athletes from individual- and team sports and in non-athletes. Psychology of Sport and Exercise, 26, 9-13. DOI:10.1016/j.psychsport.2016.05.009.

Laguna, M., Lachowicz-Tabaczek, K., Dzwonkowska, I. (2007). The Rosenberg Self-Esteem Scale - Polish adaptation of the method. Psychologia Społeczna, 2 (04), 164-176.

Leckelt, M., Küfner, A.C.P., Nestler, S., Back, M.D. (2015). Behavioral processes underlying the decline of narcissists' popularity over time. Journal of Personality and Social Psychology, 109, 856-871. DOI: 10.1037/pspp0000057.

Lee, A., Hankin, B.L. (2009). Insecure Attachment, Dysfunctional Attitudes, and Low Self-Esteem Predicting Prospective Symptoms of Depression and Anxiety During Adolescence. Journal of Clinical Child \& Adolescent Psychology, 28 (2), $219-231$ DOI: $0.1080 / 15374410802698396$.

Noordstar, J.J., Van der Netb, J., Jakc, S., Heldersb, P.J.M., Jongmansd, M.J. (2016). Global self-esteem, perceived athletic competence, and physical activity in children: A longitudinal cohort study. Psychology of Sport and Exercise, 22, 83-90. DOI: 10.1016/j. psychsport.2015.06.009.

O'Rourke, D.J., Smith, R.E., Smoll, F.L., Cumming, S.P. (2014). Relations of Parent-and Coach-Initiated Motivational Climates to Young Athletes' Self-Esteem, Performance Anxiety, and Autonomous Motivation: Who Is More Influential? Journal of Applied Sport Psychology, 26 (4), 395-408. DOI: 10.1080/10413200.2014.907838.

Piasecka, A., Kolmetz, M., Kotyśko, M., Stankiewicz, B. (2018). Subjective and objective valuation of one's physical fitness - the role of self-esteem, motivation, and the need for social approval. Journal of Education, Health and Sport, 8 (01), 280-293.

Rosenberg, M., Schooler, C., Schoenbach, C., Rosenberg, F. (1995). Global Self-Esteem and Specific Self-Esteem: Different Concepts, Different Outcomes. American Sociological Review, 60 (1), 141-156.

Solomon, S., Greenberg, J., Pyszczynski, T. (1991). A Terror Management Theory of Social Behavior: The Psychological Functions of Self-Esteem and Cultural Worldviews. Advances in Experimental Social Psychology, 24, 93-159. DOI: 10.1016/ S0065-2601(08)60328-7.

Steiger, A.E., Allemand, M., Robins, R.W., Fend, H.A. (2014). Low and decreasing self-esteem during adolescence predict adult depression two decades later. Journal of Personality and Social Psychology, 106 (2), 325-338. DOI: 10.1037/a0035133.

Strelau, J., Jaworowska, A., Wrześniewski, K., Szczepaniak, P. (2005). Coping with Stress Questionnaire. Textbook, Psychological Testing Laboratory of the Polish Psychological Association. Warszawa: Pracownia Testów Psychologicznych Polskiego Towarzystwa Psychologicznego. 
Szczepaniak, P., Strelau, J., Wrześniewski, K. (1996). Diagnosis of coping styles with the use of the Polish version of Endler and Parker's CISS. Przeglad Psychologiczny, 39, 113-146.

Tangney, Cz.P., Baumeister, R.F., Boone, A.L. (2014). High Self-Control Predicts Good Adjustment, Less Pathology, Better Grades, and Interpersonal Success. Journal of Personality, 72 (2), 271-324. DOI: 10.1111/j.0022-3506.2004.00263.x.

Terelak, J.F. (2008). Man and stress. Bydgoszcz-Warszawa: Oficyna wydawnicza Branta.

Cite this article aS: Tomczak, M., Nowak, M.A. (2019). Self-Esteem of People who Practice Sport in Relation to Their Experiencing the Flow State and Their Style of Coping With Stress. Central European Journal of Sport Sciences and Medicine, 3 (27), 83-92. DOI: 10.18276/cej.2019.3-08. 